\title{
Multistep endobronchial-endovascular approach in recurrent acute respiratory failure caused by thoracic aneurysm
}

\author{
Sandro Gelsomino, MD, ${ }^{a}$ Stefano Romagnoli, MD, ${ }^{a}$ Alberto Dragotto, MD, ${ }^{b}$

 \\ Pierluigi Stefàno, MD, ${ }^{a}$ Florence, Italy
}

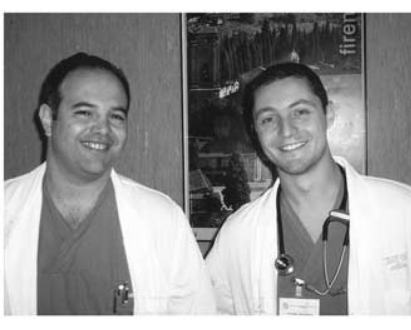

Gelsomino and Romagnoli
$\mathrm{I}$ $\mathrm{n}$ recent years, the placement of endovascular stent-graft prostheses has gained increasing popularity as a low-risk, lessinvasive, and less-traumatic procedure for thoracic aortic aneurysm (TAA) compared with traditional surgical intervention. ${ }^{1}$ Similarly, technical developments have facilitated stent implantation to restore airway patency in patients with airway obstruction. ${ }^{2}$

We describe a case of recurrent respiratory insufficiency caused by compression of the tracheobronchial tree by an extensive TAA in which we used a multistep endobronchial-endovascular technique.

\section{Clinical Summary}

A 78-year-old man with a history of TAA was admitted to the emergency department because of recurrence of respiratory failure. He was unconscious, with cyanosis and severe hypertension (220/ $120 \mathrm{~mm} \mathrm{Hg}$ ). On thoracic examination, wheezes were heard at the lower third of the left lung. Arterial blood gas analysis revealed an arterial oxygen partial pressure of $40 \mathrm{~mm} \mathrm{Hg}$, a carbon dioxide partial pressure of $120 \mathrm{~mm} \mathrm{Hg}$, and a $\mathrm{pH}$ value of 6.93 . The patient was intubated and mechanically ventilated. Preoperative chest radiography and computed tomography showed a large aortic aneurysm with compression of the tracheobronchial tree (Figure 1). Fiberoptic bronchoscopy confirmed extrinsic compression of the trachea just proximal to the carina and a significant narrowing of the left main bronchial branch 3 to $4 \mathrm{~mm}$ below the carina. After stabilization, the patient was weaned by using sedatives and extubated. Because of coexisting disease (coronary artery disease, renal insufficiency, and chronic obstructive pulmonary disease), which made the patient not an ideal operative candidate, a multistep endobronchial-endovascular intervention was planned.

In the first step the patient continued to spontaneously breathe. Sedation was achieved with intravenous remifentanil $(0.1 \mu \mathrm{g}$. $\left.\mathrm{kg}^{-1} \cdot \mathrm{min}^{-1}\right)$ and propofol $\left(3 \mathrm{mg} \cdot \mathrm{kg}^{-1} \cdot \mathrm{h}^{-1}\right)$. A 14-mm covered

\footnotetext{
From the Cardiovascular Anaesthesia and Cardiac Surgery Unit ${ }^{\mathrm{a}}$ and the Thoracic Surgery Unit, ${ }^{\mathrm{b}}$ Careggi Hospital, Florence, Italy.

Received for publication Aug 3, 2004; revisions received Aug 19, 2004; accepted for publication Sept 7, 2004.

Address for reprints: Sandro Gelsomino, MD, Segreteria Cardiochirurgia, Careggi Hospital, Viale Morgagni 85, 50134, Florence, Italy (E-mail: sandrogelsomino@virgilio.it).

J Thorac Cardiovasc Surg 2005;129:1436-8

$0022-5223 / \$ 30.00$

Copyright $\odot 2005$ by The American Association for Thoracic Surgery

doi:10.1016/j.jtcvs.2004.09.041
}

endobronchial Nitinol stent (Ultraflex stent; Boston Scientific CO, Natick, Mass) was placed in the left main bronchus with the aid of a rigid bronchoscope. A second 13-mm Y-shaped silicon stent (Tracheobronxane; Novatech, Plan de Grasse, France) was placed in the carina and right main bronchus (Figure 2, $A$ and $B$ ).

In the second step the patient was placed in the supine decubitus position on a radiolucent table and draped sterilely for emergency left thoracotomy in case serious complications ensued. Cardiopulmonary bypass standby was available. General anesthesia was induced with intravenous remifentanil $\left(0.5 \mu \mathrm{g} \cdot \mathrm{kg}^{-1} \cdot \mathrm{min}^{-1}\right)$, propofol $(2 \mathrm{mg}$. $\left.\mathrm{kg}^{-1} \cdot \mathrm{h}^{-1}\right)$, and cisatracurium $\left(200 \mu \mathrm{g} \cdot \mathrm{kg}^{-1}\right)$ and maintained with remifentanil $\left(0.25 \mu \mathrm{g} \cdot \mathrm{kg}^{-1} \cdot \mathrm{min}^{-1}\right)$, propofol $\left(3 \mathrm{mg} \cdot \mathrm{kg}^{-1} \cdot \mathrm{h}^{-1}\right)$, and cisatracurium $\left(1.7 \mu \mathrm{g} \cdot \mathrm{kg}^{-1} \cdot \mathrm{min}^{-1}\right)$. Two $3636 \mathrm{C} 114 \mathrm{~T}$ Medtronic Talent stent grafts (Medtronic, Santa Rosa, Calif) were implanted (Figure 2, A) by using the standard technique. ${ }^{1,3}$ The endotracheal tube was removed 2 hours later, and the patient was dismissed from the intensive care unit on postoperative day 1 and discharged on postoperative day 2 after an uncomplicated course.

In the third step, on postoperative day 15, the carinal stent was removed, and a new stent (Polyflex stent; W. Rüsch AG, Kernen, Germany) was positioned in the trachea (Figure 2,C).

In the fourth step, on postoperative day 147, the tracheal stent was removed. A left main bronchus metal stent was left in place.

At 1 year of follow-up, the patient is alive and functions independently. He remained asymptomatic, and no further episode of respiratory distress occurred (Figure 2,D).

\section{Discussion}

Despite substantial advances in perioperative care and surgical techniques, traditional operations for TAA are still associated with a high mortality and morbidity. ${ }^{4}$ Thus endovascular stent-graft placement has been widely used in recent years as a minimally invasive and potentially safer treatment compared with traditional surgical intervention. ${ }^{1}$ At the same time, endobronchial procedures have been developed over the past decade, and their application has greatly increased among bronchologists for the treatment of airway stenosis caused by endobronchial pathology or extrinsic compression. ${ }^{5}$ Airway stenting with silicone or expandable metal stents provides a reliable and durable dilatation in $80 \%$ to $95 \%$ of patients. Unfortunately, neither silicone nor available metal stents conform to all the ideal characteristics for an endobronchial stent. The advantages of silicone stents include ease of removal, repositioning, and customization, with the major drawbacks being stent migration and obstruction. Expandable metal stents have the advantage of ease of insertion and stability. Nonetheless, the most serious disadvantage is that it is nearly impossible to reposition or remove a stent once positioned. 

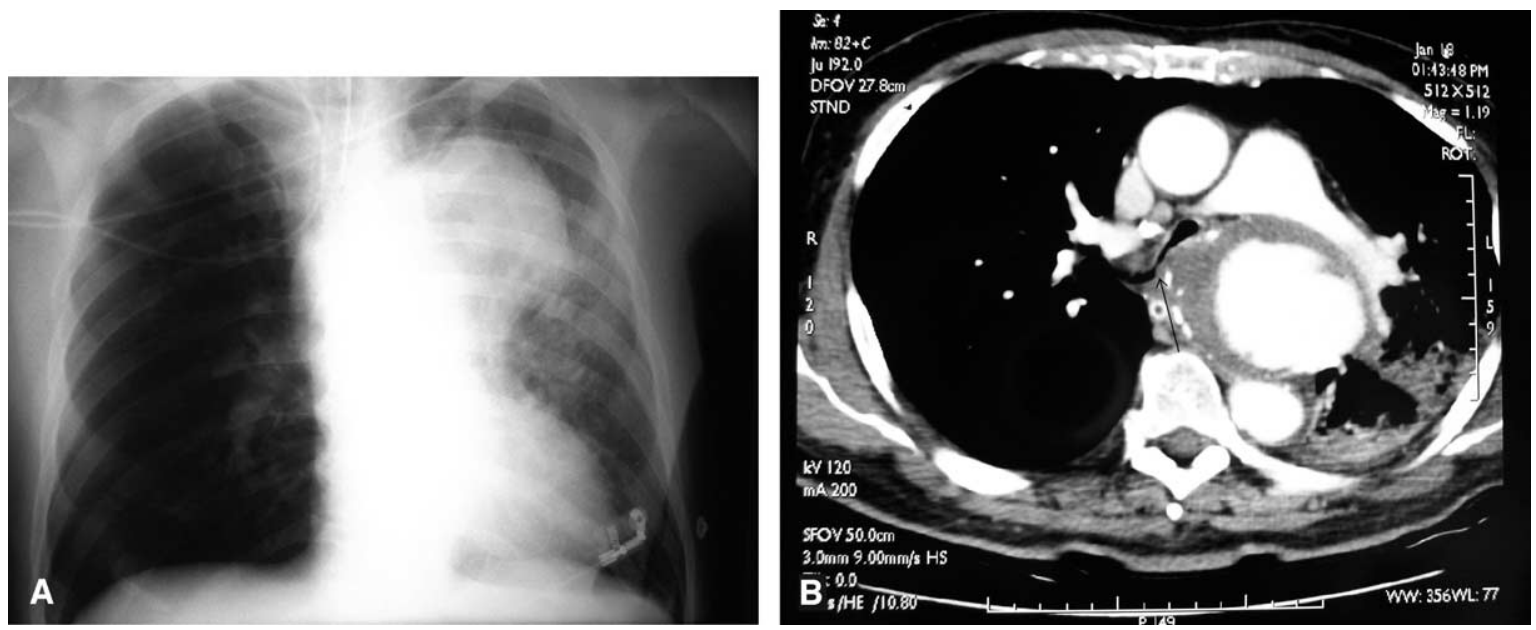

Figure 1. A, Preoperative chest $x$-ray film showing the thoracic aneurysm. B, Preoperative computed tomographic scan with intravenous contrast. The examination showed a $90-\mathrm{mm}$ dilation of the distal aortic arch and descending aorta with marked compression of the trachea (arrow), resulting in a pulmonary atelectasis of the lower lobe of the left lung.
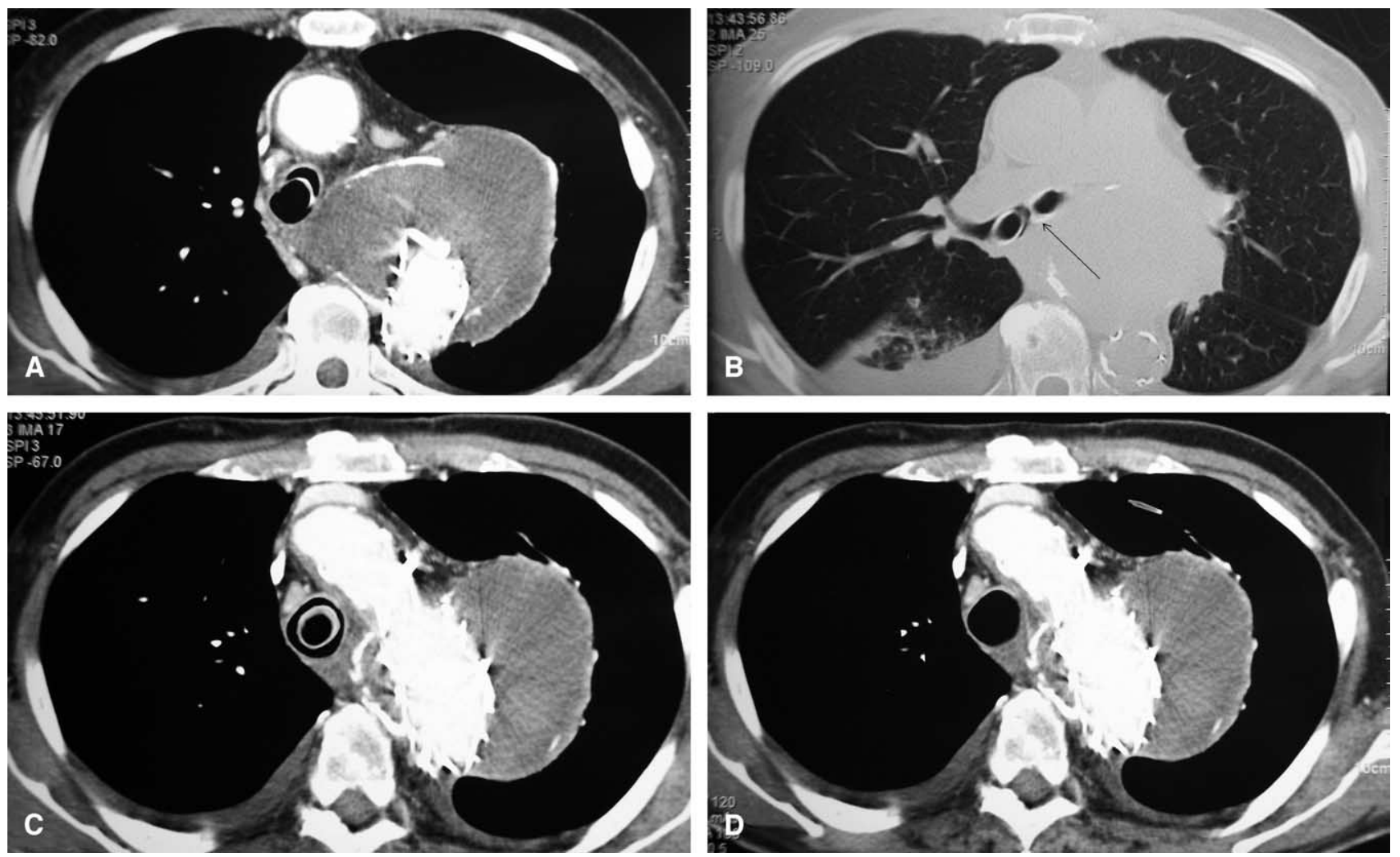

Figure 2. Endovascular stent grafts and evolution of tracheobronchial malacia at computed tomographic scanning. A, Computed tomographic scan with contrast. After stent-graft deployment, the aneurysm no longer fills with contrast. B, Computed tomographic scan without contrast. The arrow shows the carinal bifurcated stent. C, Computed tomographic scan with contrast at 148 days. The arrow shows the tracheal stent before removal. D, At 1 year, the trachea was completely patent. 
We presented a case of a patient affected by a giant aneurysm with large airway obstruction and recurrent respiratory failure. He successfully underwent a multistep, noninvasive endobronchialendovascular procedure, and as far as we know, this is the first report of TAA with airways compression similarly approached. After endobronchial placement of a 14-mm covered stent in the left main bronchus and a 13-mm Y-shaped silicon stent in the carina and right main bronchus, the patient underwent endovascular TAA repair. Further steps were carinal stent removal with positioning of a tracheal stent after 15 days and tracheal stent removal on postoperative day 147 .

In conclusion, the endobronchial-endovascular approach ensured successful management of symptoms and effective treatment of TAA, enabling an expeditious postoperative recovery and no recurrence of symptoms.

\section{References}

1. Dake MD, Kato N, Mitchell RS, Semba CP, Razavi MK, Shimono T, et al. Endovascular stent-graft placement for the treatment of acute aortic dissection. N Engl J Med. 1999;340:1546-52.

2. Madden BP, Datta S, Charokopos N. Experience with Ultraflex expandable metallic stents in the management of endobronchial pathology. Ann Thorac Surg. 2002;73:938-44.

3. Demers P, Miller DC, Mitchell RS, Kee ST, Sze D, Razavi MK, et al. Midterm results of endovascular repair of descending thoracic aortic aneurysms with first-generation stent grafts. J Thorac Cardiovasc Surg. 2004;127:664-73.

4. Mitchell RS, Dake MD, Sembra CP, Fogarty TJ, Zarins CK, Liddel RP, et al. Endovascular stent-graft repair of thoracic aortic aneurysms. J Thorac Cardiovasc Surg. 1996;111:1054-62.

5. Miyazawa T, Miyazu Y, Iwamoto Y. Stenting at the flow-limiting segment in tracheobronchial stenosis due to lung cancer. Am J Respir Crit Care Med. 2004;169:1096-102.

\title{
Caseous calcification of the mitral annulus
}

\author{
Hatem Alkadhi, MD, ${ }^{a}$ Sebastian Leschka, MD, ${ }^{a}$ René Prêtre, MD, ${ }^{\mathrm{b}}$ Aurel Perren, MD, ${ }^{\mathrm{c}}$ Borut Marincek, MD, and

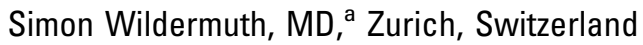

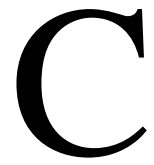

aseous calcification of the mitral annulus is a rare variant of mitral annular calcification that should be included in the differential diagnosis of intracardiac masses. ${ }^{1}$ We present the computed tomography (CT), intraoperative, and histopathologic findings of a 70-year-old woman with mitral stenosis caused by a large caseous calcification located in the posterior mitral annulus.

\section{Clinical Summary}

A 70-year-old woman was admitted with progressive shortness of breath, orthopnea, and several syncopal episodes in the last 6 months. Her history was remarkable for a long-standing hypertonia. A transthoracic echocardiogram revealed an echo-intense

\footnotetext{
From the Institute of Diagnostic Radiology, ${ }^{a}$ Clinic for Cardiovascular Surgery, ${ }^{\mathrm{b}}$ and Department of Pathology, ${ }^{\mathrm{c}}$ University Hospital Zurich, CH8091 Zurich, Switzerland.

The work was supported by the National Center of Competence and Research, Computer Aided and Image Guided Medical Interventions of the Swiss National Science Foundation.

Received for publication Oct 27, 2004; accepted for publication Nov 4, 2004.

Address for reprints: Hatem Alkadhi, MD, Department of Medical Radiology, Institute of Diagnostic Radiology, University Hospital Zurich, Rämistrasse 100, CH-8091 Zurich, Switzerland (E-mail: hatem.alkadhi@usz.ch).

J Thorac Cardiovasc Surg 2005;129:1438-40

$0022-5223 / \$ 30.00$

Copyright $\odot 2005$ by The American Association for Thoracic Surgery

doi:10.1016/j.jtcvs.2004.11.051
}

mass with central echolucencies attached to the posterior mitral annulus causing mitral stenosis. For further characterization of the lesion, a 64-slice multidetector row CT (Sensation 64, Siemens, Germany) with retrospective electrocardiographic triggering after intravenous administration of iodinated contrast material was performed. CT showed an oval $3 \times 3-\mathrm{cm}$ mass located in the posterior mitral annulus with peripheral calcifications and central hyperdensity. Reconstructions during mid-systole showed the broad-based attachment of the lesion to the posterior leaflet; during middiastole, the mass hindered a complete opening of the posterior leaflet, thus leading to mitral stenosis (Figure 1).

At surgery, the nodular, exophytic mass was excised, and a pasty, white material that filled the center of the mass was aspirated (Figure 2). The mitral valve was subsequently reconstructed with ring annuloplasty. Cultures for bacteria, fungi, and acid-fast bacilli did not yield infectious organisms, and histochemical stains showed negative results. Histopathologic examination of the pasty material showed a dense, amorphous, acellular and basophilic substance with scattered calcifications and sparse histiocytes (Figure 3). Inflammatory cells were absent. Thus, the diagnosis of caseous calcification of the mitral annulus was established.

\section{Discussion}

Mitral annular calcification is a degenerative abnormality of the cardiac fibrous skeleton that occurs mainly in elderly individuals. ${ }^{2}$ It usually involves the mid-base of the posterior leaflet but may also involve other segments of the mitral annulus. Caseous calcification is a less-known and rarely described entity representing a variant of mitral annular calcification, which is typically located in the posterior mitral annulus. ${ }^{1}$ It presents as a soft, periannular calcification and is composed of an admixture of calcium, fatty acids, and cholesterol with a "toothpaste-like" texture. The echo- 